\title{
'A heartbeat moment': qualitative study of GP views of patients bringing health information from the internet to a consultation
}

\author{
Sanjiv Ahluwalia, Elizabeth Murray, Fiona Stevenson, Cicely Kerr and Jo Burns
}

\begin{abstract}
Background

Government policy is to encourage self-help among patients. The internet is increasingly being used for health information. The literature on the role of the internet in the doctor-patient consultation remains sparse.
\end{abstract}

Aim

To determine the perceived responses of GPs to internet-informed patients in consultations and the strategies GPs use for dealing with information from the internet being brought into consultations.

Design of study

A qualitative study design was used, with semistructured interviews.

Setting

GPs based in North Central London.

\section{Method}

Analysis was conducted by a multidisciplinary team of researchers. Participants were 11 GPs: five partners, three locums, and three salaried doctors; seven were white, three were Asian, and one was of Chinese origin. The median year of General Medical Council (GMC) registration was 1989. There were six women and five men; five participants worked in training practices.

\section{Results}

GPs experienced considerable anxiety in response to patients bringing information from the internet to a consultation but were able to resolve this anxiety. The study participants learned to distance themselves from their emotional response, and used cognitive and behavioural techniques to assist them in responding appropriately to patients. These techniques included buying time in a consultation, learning from previous consultations, and using the internet as an ally, by directing patients to particular websites. The importance for doctors of feeling valued by patients was apparent, as was the effect of the prior doctor-patient relationship.

\section{Conclusion}

GPs interviewed used sophisticated mechanisms for dealing with their emotions. GPs struggling with internet-informed patients can use the mechanisms described to alleviate the difficulties.

\section{Keywords}

general practice; internet; physician-patient relations.

\section{INTRODUCTION}

Throughout the developed world, patients are increasingly encouraged to take an active role in their health and health care..$^{1-4}$ In the UK, this has been formalised in NHS policy, with an expectation that an activated (or 'fully engaged') population will lead to improved health outcomes, and reduced costs. $^{5}$ Increasing patient participation is encouraged through initiatives such as the provision of health information on the internet (for example, www.nhs.uk) and patient selfmanagement courses (for example, the Expert Patient Programme [EPP]). ${ }^{3}$ Simultaneously, and independently of government policy, patients internationally are turning to the internet for health information. ${ }^{6-8}$ Numerous concerns have been voiced about this trend, including anxieties about the effect of inaccurate or misleading information, ${ }^{9-11}$ exploitation of vulnerable people by exaggerated claims for treatments of unproven value, ${ }^{12}$ and the raising of unrealistic expectations. Bodenheimer and Grumbach fear that advances in information technology fundamentally challenge the very essence of doctor-patient consultations by 'substituting impersonal exchanges across luminescent LCD screens for the face-to-face encounters and hands-on care that produce much

S Ahluwalia, MRCGP, MSc, FHEA GP, Watling Medical Centre, Stanmore. E Murray, FRCGP, PhD, reader in primary care; $F$ Stevenson, $P h D$, senior lecturer in medical sociology; C Kerr, MSc, research fellow, University College London, Research Department of Primary Care and Population Health, London. J Burns, BA, network manager, PCRN-GL, London South Bank University, London.

Address for correspondence

Sanjiv Ahluwalia, Watling Medical Centre, 42 London Road, Stanmore, HA7 4NU.

E-mail: Sanjiv.ahluwalia@londondeanery.ac.uk

Submitted: 7 March 2009; Editor's response: 5 May 2009; final acceptance: 7 July 2009.

(c)British Journal of General Practice 2010; 60: 88-94.

DOI: 10.3399/bjgp10X483120 
of the therapeutic benefit and professional satisfaction of primary care practice' ${ }^{13}$

There are relatively few qualitative or quantitative data on this subject, and those that do exist do not support this apocalyptic view. Moreover, although some physicians report generally negative attitudes toward introducing health information from the internet into consultations, ${ }^{14}$ others are more positive. ${ }^{15}$ The proportion of patients who use the internet to find health information is increasing; ${ }^{16}$ however, the proportion who bring this information to a consultation remains relatively low. ${ }^{17,18}$ Most patients who take information from the internet to a consultation with a health professional do so because they value the doctor's opinion on this information, rather than using it to confront or make demands. ${ }^{18-20}$ Most of the available data focus on physician attitudes in general toward internet-informed patients, with little emphasis on what occurs in specific encounters.

The aim of this study was to determine the perceived responses of GPs to internet-informed patients in consultations, drawing on specific examples from their experience. It also considers the strategies GPs use for dealing with information from the internet being brought into consultations.

\section{METHOD}

\section{Research design}

Semi-structured interviews were conducted, with a purposive sample of GPs actively engaged in clinical care.

\section{Sample}

The aim was to recruit a sample with maximum variability in factors known to affect communication skills and the doctor-patient relationship, including sex, ${ }^{21}$ ethnicity, ${ }^{22}$ the age (full General Medical Council [GMC] registration date was used as a proxy for participants' ages) and length of experience of practitioners, ${ }^{23}$ and level of postgraduate education. ${ }^{24}$ Recruitment continued until no new themes emerged from additional interviews.

Prospective participants were initially identified by writing to all local practices in North Central London. Due to a poor response, the researchers then advertised in local postgraduate education centres and out-of-hours service providers, and approached personal contacts. New participants were also identified through those that had already participated - a technique referred to as snowballing.

All the GPs recruited worked in North Central London, which is a metropolitan area with a mixed

\section{How this fits in}

Internet use for healthcare information by patients is on the increase, and some physicians may feel challenged by patients bringing internet information into the consultation. Internet-informed patients can induce a sense of anxiety among GPs, who fear losing control of the consultation, being seen as ignorant, and being devalued by the patients. GPs use sophisticated consultation techniques to deal with the sense of anxiety generated by internet-informed patients. The prior doctor-patient relationship has an impact on the way health information from the internet is handled within the consultation.

population of high and low socioeconomic-status populations.

\section{Data collection}

Interviews were conducted from October 2006 to October 2007. A critical incident technique was employed. Participants were asked to reflect on two consultations where patients had brought information from the internet into the consultation, - one that went well and another that went badly. They were asked to describe the consultation, and then reflect on their thoughts, emotions, and behaviours during the consultation. They were also asked for their perceptions of how these reactions influenced the consultation and how they thought it might affect the doctor-patient relationship.

All interviews were conducted by a GP, who had been trained in interviewing and communication skills. The data were digitally recorded and transcribed verbatim. To prevent loss of non-verbal information, the interviewer also kept field notes. Interviews lasted between 35 and 75 minutes.

\section{Data analysis}

Data analysis was performed by a multidisciplinary team of two GPs, a sociologist, and health psychology and health service researchers, all of whom had extensive experience in qualitative research and had undertaken research in e-health and/or the doctor-patient relationship. The 'framework' approach to analysis was used. ${ }^{25}$ The advantage of this approach, which is similar to thematic analysis, is that it provides systematic and visible stages to the analytic process, is inductive, and allows for a priori as well as emergent concepts. Data were handled using the software programme NVivo 7. Data analysis was conducted concurrently with data collection, allowing for emergent themes to be tested in later interviews.

\section{RESULTS}

\section{Sample characteristics}

Eleven GPs were interviewed. Of these, five were GP 
Table 1. Participant details.

\begin{tabular}{llccccc} 
GP number & Role & Ethnicity & Date of full GMC registration & Sex & \multicolumn{2}{c}{ Training practice } \\
\hline 1 & Partner & Asian & 1987 & Female & Yes \\
\hline 2 & Partner & White & 1990 & Female & Yes \\
\hline 4 & Salaried & Chinese & 1997 & Female & No \\
\hline 5 & Locum & White & 1961 & Male & No \\
\hline 6 & Locum & White & White & 1001 & Female & No \\
\hline 7 & Locum & White & 1989 & Female & No & Yes \\
\hline 9 & Partner & Asian & 1981 & Male & Yes \\
\hline 10 & Partner & White & 1983 & Male & No \\
\hline 11 & Partner & Asian & 1987 & Female & Yes \\
\hline
\end{tabular}

principals and partners, three were locums, and three were salaried doctors. Seven were white, three were Asian, and one was of Chinese origin. The median year of full GMC registration was 1989. There were six women and five men. Five participants worked in training practices. All participants worked in separate practices other than participants 8 and 10, who worked in the same practice (Table 1).

\section{Findings}

Overall, GPs expressed a general sense of negativity about patients using the internet for health-related information:

'I think the whole concept of patients coming with things from the internet almost has a stigma attached, particularly in the GP magazines, there are jokes about it and people tend to talk about it in a predominantly negative way because GPs feel very defensive.' (GP5)

'I wasn't terribly happy about patients using the internet, they all seemed to come to me with things I'd never heard of and very often with things which seem rather bizarre or inappropriate.' (GP8)

However, some GPs did welcome patients introducing internet information in the consultation:

'... it's a bit of a heart sink when patients bring clippings from a newspaper and I never feel that when they bring sheets from the internet.' (GP4)

'I am usually quite excited about people having looked at the internet because actually then they have got some health beliefs that I can work with.' (GP1)
This negativity appeared to both contribute to, and reflect, GPs' initial responses to patients bringing information from the internet to a consultation. The study analysis revealed three main themes, which were:

- initial reactions to patients bringing information from the internet into the consultation;

- techniques employed in the consultation to overcome these initial reactions; and

- the importance of the prior doctor-patient relationship.

\section{Initial reactions to patients bringing information from the internet into the consultation}

The most commonly expressed emotion was anxiety:

'I would certainly have a heartbeat moment when they mentioned it.' (GP2)

'Her feelings of anxiety affected me and I began to feel under pressure and anxious as well ...' (GP6)

'I thought, "Oh God, how am I going to deal with this?".' (GP11)

'Frustration, irritation, disappointment, they would tend to go along with that chap anyway, but certainly up a notch, heightened.' (GP8)

Unpicking the reasons for this 'heartbeat moment' revealed three interlinked issues:

- fear of being perceived as ignorant or incompetent;

- fear of loss of control of the consultation; and

- fear of being undervalued or devalued. 
Fear of being perceived as ignorant or incompetent. The internet permits access to knowledge that was previously the domain of the 'professional'. The widespread availability of medical knowledge made GPs fear patients who come with information the GP has not come across, and therefore that they would be perceived as incompetent by the patient:

'... because I think sometimes there's a fear that patients expect you to know everything and sometimes it's hard to admit that you don't know.' (GP5)

'I am threatened by the possibility that they have read something that I don't actually know and understand.' (GP2)

Fear of loss of control of the consultation. GPs feared that patients introducing information from the internet into a consultation would alter the course of a consultation away from the GP's control:

"“... this is what I want, give it to me", so it felt quite aggressive and it made me feel defensive and that automatically made me feel on the back foot and out of control actually.' (GP5)

This could be caused by factors such as patient expectations being raised by internet information; patients being made excessively anxious by internet information; and the time taken to rectify misconceptions among patients who had encountered misleading or inaccurate information.

Fear of being undervalued or devalued. GPs perceived some patients valued information from the internet above that provided by the GP themselves, or other health professionals:

'For me that was the irritation, that the patient had far more trust in the computer and what they found on the web than in what I was trying to explain.' (GP2)

However, where GPs perceived patients valued their opinion, they felt the internet could be a useful tool in consultations, as patients could be directed to accurate, relevant information:

'Well, she had come to see me and wanted to know what I thought. She had the information from the internet but still wanted my opinion in the matter. She also came in and did not tell me what to do, she did not see me as a simple route to referral. Because she had come in having read the information and done her homework, it meant we could have a discussion about the treatments etc, which was more advanced than if she had not read about her options. This would have meant starting from scratch.' (GP6)

\section{Techniques employed in the consultation}

GPs responded to this perceived shift in balance of power and access to knowledge in consultations with reflexiveness, and behavioural changes. Responders identified the need for reflection, both within and outside of the consultation, to help them move on from the emotional response triggered by patients bringing internet information to the consultation:

'I think I tend to learn from experience, so if over the last 10 times people have been on the net and nine of those were positive I would start thinking "ah well this is actually a positive thing", whereas if those 10 had actually been negative I would certainly have a heartbeat moment when they mentioned it.' (GP2)

GPs described recognising the emotion, and then deliberately adopting behaviours that would both provide time to allow the anxiety to dissipate, and demonstrate to the patient that they were interested in, and open to, the information being brought. This included asking open questions, and adopting deliberately open body language:

'Take a deep breath in! A pause, some time to reflect.' (GP1)

'As I have got more experienced, I think actually what I have tried to do is to say "OK I am now thinking 'heart sink' ..." So I think it is probably just acknowledging that you are not feeling great about this consultation, but saying "I am going to try and put that aside and try and get on with it" and that is the approach I try.' (GP9)

Open questions were identified as allowing the patient to feel 'listened to', while giving the GP time to digest information. GPs also sought to establish patients' views of how the internet information applied to them, and what their reasons for introducing it into the consultation were.

GPs reported using specific behaviours to overcome their fear of being seen as ignorant or incompetent. These included deliberately admitting to a lack of knowledge, and demonstrating respect for the information. Many responders reported admitting ignorance to be personally challenging, but found that it became easier as they became more confident in their own abilities: 
'... if it is something rare and minutiae I'd probably come clean and say, "I'm more of a generalist and this is a very rare condition, but I am quite prepared to do a little search".' (GP3)

Showing respect for the information was seen as a way of ensuring patients felt respected and listened to, and as a way of encouraging patients to continue to engage in self-care:

'I would like to give it some attention, read it and put some thought to it.' (GP1)

'... it might have been helpful to get a chance to look at the material from the internet, assess the quality of the information, the website it came from and discuss the information with the mum.' (GP6)

An extension of this behaviour was when participants themselves introduced health information from the internet into consultations. Some GPs described directing patients to particular trusted websites both within the consultation, and as 'homework' for the patient to do later.

"There are some patients where you say, "oh I think it is this", and they say, "oh I'm going to Google ${ }^{\text {tm }}$ that", and you can suggest to them some websites that you have been to that you know give the information in a readable stance. I am quite a big fan of www.patient.co.uk, which has most everything on it, so that is a useful website that I use to try and help the patients.' (GP3)

Finally, GPs commented that they reflected on consultations that had not gone well and used these as learning experiences with a view to changing future behaviours in consultations. Many participants found that as they gained experience with consultations including internet information, they became more comfortable, and their levels of initial anxiety subsided:

'... it didn't feel like a positive consultation and so I reflected on where it didn't go well when I did try to reduce the value of the information they were bringing before I even looked at it. It stuck with me; I remember it not going well and thinking, trying to work out how I could do it better.' (GP5)

\section{Importance of the prior doctor-patient relationship}

The quality of the prior doctor-patient relationship had a significant effect on the way internet-related health information was handled within a consultation. A good prior relationship meant that GPs did not feel threatened when patients introduced such information to a consultation, and enabled the GP to perceive use of the internet as a positive tool for promoting health. A poor-quality GP-patient relationship meant that the introduction of internet information made the GP feel unvalued, leading to further stress within the doctor-patient relationship:

'I feel probably the main thing I respond to is the patient and the first patient I have a very good relationship with. I suppose maybe it is about being valued by the patient, I felt that she valued my opinion, she had come to discuss it with me and asked me what my take on it was, whereas the second patient, my recollection is, was much more, "look you know, l've found something out and you didn't tell me, you didn't know". So I suppose it was the way the information was used by the patient and that might reflect the previous relationship with the patient already.' (GP2)

'I think if you have established a good rapport, if you have a good relationship then almost anything is manageable, so I think if you have a good rapport with a patient over months or years, anything that they bring, be it a new distressing symptom or an adverse event within the practice, you have got the bedrock to build on that.' (GP9)

\section{DISCUSSION}

\section{Summary of main findings}

It was found that GPs experienced considerable anxiety in response to patients bringing information from the internet to a consultation. However, the participants had learnt to distance themselves from their emotional response, and to use cognitive and behavioural techniques to assist them in responding appropriately to patients. These techniques included buying time in a consultation, learning from previous consultations, and using the internet as an ally, by directing patients to particular websites. The importance for doctors of feeling valued by patients was apparent, as was the effect of the prior doctor-patient relationship.

\section{Strengths and limitations of the study}

Data analysis was conducted by a multidisciplinary team concurrent to interviews, so that new themes could be tested as they emerged. Semi-structured interviews were used, as they had the benefit of allowing an in-depth exploration of emotions, 
cognitions, and behaviours, and the reasons underpinning these. ${ }^{25}$

By having a GP do the interviews, the aim was to enhance trust between interviewee and interviewer, enabling the expression of socially undesirable responses, such as difficulties experienced with enabled or 'pushy' patients.

The participants were from a range of ethnic backgrounds, with a broad spread of ages and dates for full registration with the GMC. They worked in different ways within general practice, ranging from locums to partners.

The main problem with this study is the small number of interviewees - a total of 11. Among the GPs who agreed to be interviewed, no new themes or information arose in later interviews. However, despite 18 months of trying, it was not possible to interview GPs who admitted to strong negative views about patients bringing information from the internet to consultations, despite anecdotal reports suggesting the existence of these views. It can be speculated that GPs with strong negative views have a similar emotional response to the interviewees in the present study, but perhaps do not have the reflective and communication skills to enable them to move beyond this initial 'heartbeat moment'.

\section{Comparison with existing literature}

Impact of the internet on the GP-patient consultation. This study appears to be among the first to describe GPs' emotional, cognitive, and behavioural reactions to patients introducing health information from the internet to a consultation. The sparse existing data support the study findings. The sense of anxiety triggered by internet-informed patients has also been described by Ahmad et al, in a focus group study of Canadian GPs. ${ }^{14}$ As with the present study, the Canadian doctors described problems with poor-quality online information, the time taken in dealing with internet information, and a feeling their expertise was being challenged. The use of 'trusted' internet sites as an ally in such consultations appears to be growing, with over $50 \%$ of Australian GPs reporting this behaviour in a postal survey. ${ }^{26}$ It is unclear how GPs develop their list of 'trusted sites'. The present study participants' intuitive desire to demonstrate respect for the information brought by the patient appears to be supported by the finding that US patients were more satisfied with doctors who took such information seriously. ${ }^{27}$

The balance of power in the doctor-patient relationship. Social change is resulting in a more equitable balance of power between GPs and patients. ${ }^{28}$ The present study highlighted that internet-informed patients proved challenging to GPs. GPs have responded to this shifting balance in power by reshaping their role from gatekeepers of secondary care services to facilitators of information interpretation and decision making, to help patients make informed choices about their journey through the healthcare system..$^{28}$ In this context, the consultation techniques described by the GPs in this study could be seen to demonstrate a significant effort to engage patients in the process of the consultation.

Reflection and learning. The GPs in the study described their initial reaction to internet-informed patients, the use of patience and reflection (both inaction and on-action), ${ }^{29}$ to think about how to deal with these patients, and their subsequent use of consultation techniques to respond to patients. Many of these steps have similarities with Kolb's adult learning theory. ${ }^{30}$ There are significant implications with this observation - reflection is a powerful tool to help resolve difficult situations in clinical practice; learning to deal with internetinformed patients is an iterative process - one improves with experience using reflection to support learning; but most importantly, participants demonstrated that it is never too late to be able to learn to adapt and deal with challenging situations and patients.

\section{Implications for clinical practice}

This study highlights the challenges faced by GPS when dealing with internet-informed patients. The study participants used sophisticated mechanisms for dealing with their emotions during the course of the consultation. The use of reflection and experience in dealing with internet-informed patients highlights that these mechanisms can be learned. GPs struggling with internet-informed patients can use the mechanisms described in this paper to help alleviate the difficulties.

\section{Funding body}

NOCLOR provided funding for Sanjiv Ahluwalia's time involved in data collection

\section{Ethical approval}

This study received ethical approval (06/Q0509/29) from the Barnet, Enfield and Haringey Research Ethics Committee Department of Research \& Development, Royal National Orthopaedic Hospital NHS Trust. All participants provided written informed consent before participation in the research

\section{Competing interests}

The authors have stated that there are none. The study sponsors and funder played no role in the study design, data collection, data analysis, or writing up. The authors have no financial connections with the study funder

\section{Acknowledgements}

The authors acknowledge the involvement of the participants involved in this study. 


\section{Discuss this article}

Contribute and read comments about this article on the Discussion Forum: http://www.rcgp.org.uk/bjgp-discuss

\section{REFERENCES}

1. Bodenheimer T, Lorig K, Holman H, Grumbach K. Patient selfmanagement of chronic disease in primary care. JAMA 2002; 288(19): 2469-2475.

2. Newman S, Steed L, Mulligan K. Self-management interventions for chronic illness. Lancet 2004; 364(9444): 1523-1537.

3. Department of Health. The expert patient: a new approach to chronic disease management for the 21st century. London: HMSO, 2001. http://www.dh.gov.uk/en/Publicationsandstatistics/Publications/Pub licationsPolicyAndGuidance/DH_4006801 (accessed 9 Dec 2009).

4. Department of Health. Self care - a real choice: self care support - a practical option. London: HMSO, 2005.

5. Wanless D. Securing our future health: taking a long-term view. London: HMSO, 2002. http://www.hmtreasury.gov.uk/consult_wanless_final.htm (accessed 16 Dec 2009).

6. Dutton W, Helsper EJ. The internet in Britain: 2007. Oxford: Oxford Internet Institute, University of Oxford, 2007.

7. Fox S. Online health search 2006. Washington DC: Pew Internet and American Life Project, 2006

8. Fox S. The engaged E-patient population. Washington, DC: Pew Internet and American Life Project, 2008.

9. Eysenbach G, Diepgen TL. Towards quality management of medical information on the internet: evaluation, labelling, and filtering of information. BMJ 1998; 317(7171): 1496-1500.

10. Robinson TN, Patrick K, Eng TR, Gustafson D. An evidence-based approach to interactive health communication: a challenge to medicine in the information age. Science Panel on Interactive Communication and Health. JAMA 1998; 280(14): 1264-1269.

11. Jadad AR, Gagliardi A. Rating health information on the Internet: navigating to knowledge or to Babel? JAMA 1998; 279(8): 611-614.

12. Heathfield H, Pitty D, Hanka R. Evaluating information technology in health care: barriers and challenges. BMJ 1998; 316(7149): 1959-1961.

13. Bodenheimer T, Grumbach K. Electronic technology: a spark to revitalize primary care? JAMA 2003; 290(2): 259-264.

14. Ahmad F, Hudak PL, Bercovitz K, et al. Are physicians ready for patients with Internet-based health information? J Med Internet Res 2006; 8(3): e22.

15. Newnham GM, Burns WI, Snyder RD, et al. Attitudes of oncology health professionals to information from the Internet and other media. Med J Aust 2005; 183(4): 197-200.

16. Atkinson NL, Saperstein SL, Pleis J. Using the internet for healthrelated activities: findings from a national probability sample. J Med Internet Res 2009; 11(1): e4.

17. Malone M, Harris R, Hooker R, et al. Health and the internet changing boundaries in primary care. Fam Pract 2004; 21(2): 189-191.

18. Murray E, Lo B, Pollack L, et al. The impact of health information on the internet on the physician-patient relationship: patient perceptions. Arch Intern Med 2003; 163(14): 1727-1734.

19. Hart A, Henwood F, Wyatt S. The role of the internet in patient-practitioner relationships: findings from a qualitative research study. J Med Internet Res 2004; 6(3): e36.

20. Murray E, Lo B, Pollack L, et al. The impact of health information on the internet on health care and the physician-patient relationship: national US survey among 1050 US physicians. J Med Internet Res 2003; 5(3): e17.

21. Roter DL, Hall JA. Physician gender and patient-centered communication: a critical review of empirical research. Annu Rev Public Health 2004; 25: 497-519.

22. Ferguson WJ, Candib LM. Culture, language, and the doctor-patient relationship. Fam Med 2002 May; 34(5): 353-361.

23. Choudhry NK, Fletcher RH, Soumerai SB. Systematic review: the relationship between clinical experience and quality of health care. Ann Intern Med 2005; 142(4): 260-273.

24. McKinstry B, Guthrie B, Freeman G, Heaney D. Is success in postgraduate examinations associated with family practitioners' attitudes or patient perceptions of the quality of their consultations? A cross-sectional study of the MRCGP examination in Great Britain. Fam Pract 2005; 22(6): 653-657.

25. Hancock C. An introduction to the research process. Nottingham: University of Nottingham, 2002.

26. Sim MG, Khong E, Jiwa M. Does general practice Google? Aust Fam Physician 2008; 37(6): 471-474.

27. Bylund CL, Gueguen JA, Sabee CM, et al. Provider-patient dialogue about internet health information: an exploration of strategies to improve the provider-patient relationship. Patient Educ Couns 2007 66(3): 346-352.

28. Laing M, Hogg G, Winkelman D. The impact of the internet on professional relationships: the case of health care. The Service Industries Journal 2005; 25(5): 675-687.

29. Schon DA. The reflective practitioner: how professionals think in action. New York: Basic Books, 1983.

30. Kolb DA. Experiential learning: experience as the source of learning and development. Englewood Cliffs, NJ: Prentice-Hall, 1984. 